\title{
Construction and application of reservoir development measure benefit evaluation system
}

\author{
Dan Han ${ }^{1, a}$, Debin Zhang ${ }^{1}$ \\ ${ }^{1}$ Onshore oilfield operation area of Petro China Jidong Oilfield, Tangshan, Hebei, China.
}

\begin{abstract}
The reservoir passes the peak of reserves.The reserves of new investment and development are decreasing year by year. The reserve resources are insufficient. Some of the main development units have entered the stage of secondary or tertiary oil recovery. The dependence of stable oil and gas production on measure production increases continuously. Under this background, the workload of oil well measures increases year by year. It is difficult to control the operation cost of measures. As a result, the overall economic benefits of oilfield enterprises have been declining year by year.The cost of ineffective measures has become an important factor restricting the economic development of oilfields. Through the construction of measures benefit evaluation system. Strengthen the controllability and predictability of each stage of implementation. Special attention should be paid to the pre control management of high cost wells and the transformation of production mode of low efficiency wells. Strictly follow the "ex ante argument, adjustment in matters, and post evaluation optimization" measures to run the management mode. Realize the reasonable allocation of workload and cost, and improve the effective rate of return of funds.
\end{abstract}

\section{Preface}

Jidong onshore oilfield has entered the stage of slow growth after the peak of reserve discovery.The newly invested and developed reserves are decreasing year by year.At present, the reserve of recoverable reserves is insufficient. Some of the main development units have entered the stage of secondary oil recovery or tertiary oil recovery.Some of the main development units have entered the stage of secondary oil recovery or tertiary oil recovery. The completion of annual output depends on the output of measures. It is higher than the average level of Bohai Bay oilfield. Under this influence, on the one hand, the workload of measures has increased year by year. It is difficult to control the operation cost of measures.On the other hand, the overall economic benefits of the measures are declining year by year. The increase of invalid measures investment has become an important factor restricting the economic development of oil fields. Therefore, around the main line of increasing production.Reducing cost and improving efficiency.Taking the continuous upgrading of measures management as the goal.Construction of a systematic evaluation system for the whole process of measures. It has become one of the important ways to control the cost of oil and gas development and improve economic benefits.

\section{THE CURRENT SITUATION OF MEASURES BENEFIT MANAGEMENT AND THE CAUSES OF LOW EFFICIENCY}

\subsection{The effectiveness of measures is lack of the whole process evaluation and control}

From researching formulation to implementation, the measures have not established an effective communication and coordination mechanism and lack of whole process control. There are three main adverse effects. First of all, pre evaluation is only conducted from the perspective of increasing oil production of single well The single evaluation of increasing oil is lack of pertinence. Secondly, in the initial stage of the measure implementation, the abnormal measure wells were not timely tracked evaluated and treated in time. Resulting in the loss of measure production, and even some wells could not be recovered. Thirdly, after the implementation of the measures.Only a simple evaluation of the current year's benefits is carried out.Lacking of big data analysis and application which can not provide optimization reference for the implementation of follow-up measures.

\subsection{Inefficient and ineffective measures have not been effectively avoided before implementation}

On the one hand, the formulation of measures is based on 
the production demand and reservoir demand.And the benefit factors are not considered enough. On the other hand, the pre evaluation of measures does not establish an effective control mechanism which demonstrates the deficiencies from different levels.

\section{Construction of benefit evaluation system of development measures}

\section{1 build a three-level evaluation system of measures and benefits to realize the whole process control}

We should follow the production and operation integration order of efficiency as the center production as the foundation and reserves as the basis. Regional review of scheme and operation approval.

\subsection{Pre evaluation system of measures}

Oil and water well measures research is strictly in accordance with the comprehensive adjustment plan of reservoir development. Based on the fine reservoir description and guided by the development technology policy. The technical personnel of Geological Research Institute and oil production area put forward specific measures through reservoir dynamic analysis. The reservoir dynamic analysis fully combines the dynamic and static state data and dynamic monitoring data of oil wells to improve the accuracy of measure research. The technical personnel of the technology research institute shall demonstrate the feasibility of the process and be responsible for determining and optimizing the construction process.

\subsubsection{Launch technology research, develop technology policy, and optimize guiding measures.}

Through the development of water injection unit liquid extraction, deep pumping, fracturing measures development technology policy research. Guide the reasonable development and production of reservoir. Taking the liquid extraction technology policy as an example, through the combination of reservoir numerical simulation and reservoir engineering method, different technical policy schemes are designed with the highest recovery degree as the goal. So that the well selection and production parameter adjustment after the implementation of measures can be relied on. The in-depth study of development technology policy is of great significance for scientific guidance measures optimization.

\subsubsection{Take oil reservoir and small layer as the main body. Carry out collaborative research, and achieve results in scale implementation.}

The proportion of comprehensive treatment measures has increased year by year. With an average proportion of $66 \%$ in the past three years. Facing the current situation of structural transformation, in view of the dynamic and static contradictions existing in the development and production. And based on the dynamic response of the reservoir, the geological characteristics of the reservoir are re recognized and the stratigraphic division and comparison are readjusted. According to the correlation results, the sequence stratigraphic framework of single sand body level in the oilfield is established. From the determination of sand body source direction, the vertical distribution characteristics of sand body in different provenance directions. The plane distribution shape and physical property change of sand body. The depth analysis of sand body distribution and physical property difference is carried out which provides data basis for the adjustment of development plan and 3D reservoir geological model. On this basis, the annual measure structure adjustment.Monthly measure implementation structure and operation arrangement are all based on small layer and reservoir.Based on dynamic response and the principle of oil and water well coordinated treatment achieve scale effect.

\subsection{Measure pre evaluation and improvement chart to realize visual evaluation at different levels}

The original pre evaluation chart mainly classifies and evaluates the benefits of measures according to the oil price. However, under the current investment structure and considering the cost per ton of oil of the current measures. It is one-sided to pre evaluate the reserve measures only from the perspective of oil price which can not meet the evaluation needs at different levels. The improved version mainly classifies the pre evaluation measures from three aspects: The basic operation angle at the Geological Institute level. The operation cost considering the personnel cost at the operation area levelT and the production cost considering the depreciation and depletion at the oilfield level. Through pre evaluation, the oil well measures are divided into four categories as follows:

Table 1. Classification measures by evaluation.

\begin{tabular}{|c|c|c|}
\hline Grade & Discriminant & Unit \\
\hline $\begin{array}{c}\text { A class of } \\
\text { measures }\end{array}$ & $\mathrm{C}$ ton $<\mathrm{C}$ base & $\begin{array}{c}\text { C ton: input of } \\
\text { measures per ton of } \\
\text { oil, yuan; C basis: } \\
\text { basic operating cost } \\
\text { per ton of oil in } \\
\text { operation area, yuan. }\end{array}$ \\
\hline $\begin{array}{c}\text { Class II } \\
\text { measures }\end{array}$ & $\begin{array}{c}\mathrm{C} \text { operation }>\mathrm{C} \\
\text { ton }>\mathrm{C} \text { base }\end{array}$ & $\begin{array}{c}\text { C operation: } \\
\text { Operating cost per ton } \\
\text { of oil, yuan. }\end{array}$ \\
\hline $\begin{array}{c}\text { Class III } \\
\text { measures }\end{array}$ & $\begin{array}{c}\mathrm{C} \text { production }>\mathrm{C} \\
\text { ton }>\mathrm{C} \text { operation }\end{array}$ & $\begin{array}{c}\mathrm{C} \text { production cost per } \\
\text { ton of oil, yuan. }\end{array}$ \\
\hline $\begin{array}{c}\text { Invalid } \\
\text { measures }\end{array}$ & $\begin{array}{c}\mathrm{C} \text { production }<\mathrm{C} \\
\text { tons }\end{array}$ & \multicolumn{2}{|c}{} \\
\hline
\end{tabular}




\section{Establish measure evaluation system}

\subsection{Establish the integrated evaluation system of storage and production}

The economic evaluation of reservoir and development and production measures is relatively single. And the objective is limited to the short-term benefit evaluation of production. The evaluation method is mainly based on incremental benefit evaluation. And the evaluation index is difficult to objectively and truly reflect the current situation of long-term and hidden benefits. At the same time, there is a blank in evaluating the long-term benefits of recoverable reserves and development indicators in the whole life cycle of the evaluation object. Therefore, starting from the calculation of recoverable reserves, the calculation model of increasing reserves and increasing production is established on the basis of the static elements system framework and correlation research of development units and production measures. So as to complete the comprehensive evaluation.

Calculation model of reservoir increase by measures:

$$
y=-0.0084 S_{0}+0.0049 D+1.0025 a_{p}-0.004 \mathrm{c}
$$

Which: $S_{0}$-remaining oil saturation; $D$-reservoir thickness; $\quad a_{p}$-formation pressure coefficien; c-deep reservoir burial; $y$-increased oil production.

Measure reserve income model:

$$
E I=\left(P_{0}-T_{a x}\right)\left(\triangle Q_{0}+N_{R}\right)+\triangle q_{g} \beta_{\mathrm{g}}\left(p_{\mathrm{g}}-T_{g x}\right)-I
$$

Which: $P_{0}$-crude oil price; $T_{a x}$ crude oil additional tax; $\triangle Q_{0^{-}}$cumulative oil increment; $N_{R^{-} \text {incremental }}$ recoverable reserves; $\triangle q_{g}$-cumulative gas increment; $\beta_{\mathrm{g}}$-commodity rate of natural gas; $p_{\mathrm{g}}$ - natural gas price; $T_{g x}$-natural gas additional tax; $I$-measure cost input.

\subsection{Strengthen the analysis of life cycle data and guide the optimization and adjustment of implementation plan}

\subsubsection{Adjustment of yield structure}

According to the historical production data and the current production structure, trend fitting is carried out to forecast the production in the future. Combined with the release of the plan, the output structure is adjusted in time. The main adjustment objects are natural production.Measure production and new well production. So as to meet the production demand in the current stage and in the future.

\subsubsection{Cost structure adjustment}

Taking the annual production as the target, and based on the comprehensive treatment scheme of reservoir consolidation. The cost structure is adjusted in time and the resource allocation is reasonably optimized by analyzing the historical cost composition data and decomposing the current cost overrun.

\subsubsection{Implement structural adjustment and optimization}

Through the analysis of the historical implementation of the measures, the adaptability of the measures is studied for different development units. And the structure is adjusted in time. For the wells with low input and high output, the reduction range is reduced and the proportion of measures is increased.For the wells with high input and low output, the reduction range is increased and the proportion of measures is reduced.For the wells with high input and high output according to the actual production performance, the measures are adjusted in time. We should carry out detailed argumentation and implement it carefully.

\section{Application effect}

Through the wide application of the three-level evaluation system of measures, the coverage rate of measures has been $100 \%$. The cost of inefficient and ineffective measures has been greatly reduced and the results of cost reduction and efficiency increase are obvious. Based on the construction and analysis of data resources in the whole life cycle, the comprehensive adjustment of reservoir and the return of benefit status to a reasonable category are realized. The oil sand body controlled by single well is taken as the smallest investigation unit in shallow natural water drive reservoir. The potential dissection is carried out layer by layer and well by well by using reserve method to realize efficient potential tapping. Through optimizing and adjusting the implementation structure and consolidating the foundation of sustainable development. We should adhere to the requirements of controlling the total amount of oil and water well measures. Optimizing the structure of oil well measures and giving priority to the implementation of measures to improve the water drive control reserves. At the same time, we should ensure the coordinated management of oil and water wells. AFt the same time, reduce the hole filling, recovery and sticking with unclear remaining oil potential and unclear corresponding effective potential of oil and water wells Water plugging and other measures have reduced the total amount of measures and improved the effect of measures.

\section{References}

1. Xiao $\mathrm{Wu}$, Han Dan, Liu Zhibin et al. Oil field stimulation prediction based on fractional differential simulation model $[\mathrm{J}]$. Science, technology and engineering.2020,20 (16) 6444-6451.

2. Li Defu Guo Haixiang.. Oilfield development benefit Evaluation method and Case Study [M]. Beijing: China University of Geosciences Press, publishing year: 2013.

3. Zhang Yu, WANG Jianfeng, Qian Qian, et al. Evaluation method of economic benefit of 
secondary Development of Karamay Oil Field [J]. Xinjiang Petroleum Geology, 2010, (5) : 551-553.

4. Lu qi. Research on evaluation method of oil well measures to increase oil efficiency $[\mathrm{J}]$. Contemporary petrochemical technology.2020,24 (11) : 45-49.

5. Yang Yuanming,Li Zhiping,Lai Fengpeng,et al.Study on prediction method of effect of oil well production incresce measures[J].Science and Technology and Engineering,2013, 2013 (20) :5928-5930.

6. Jiang Jicheng,Zhang Cunguang. Study on evaluation index system of well stimulation measures[J].Inner Mongolia Petrochemical Industry2010, (14) : 18-19.

7. Wei Ping. Production models and methods for old oil Wells [J].Production models and methods for old oil Wells. 2013, (12): 146-146.

8. Dong Tian tian. Study on Economic Benefit Evaluation Method of K Oil Field Measures [J]. Inner Mongolia Petrochemical Industry, 2015, (21) :19-21.

9. Yan Jiannian, Hou Guiting, Li Jijun, etc. Research on economic benefit prediction and post-evaluation of measures input in middle and late oilfield development $[\mathrm{J}]$. Natural gas geoscience. 2012,5:973-978.

10. Li Li. Study and application of economic evaluation method of oil well production measure[J].Chemical Trade of China2013, (11) : 382-383. 